\title{
Predictors of stunting and thinness in post-menarcheal adolescent girls in rural Bangladesh
}

\author{
Jee H Rah ${ }^{1}$, Parul Christian ${ }^{1, *}$, Abu Ahmed Shamim², Ummeh T Arju², \\ Alain B Labrique ${ }^{1}$ and Mahbubur Rashid ${ }^{2}$ \\ ${ }^{1}$ Center for Human Nutrition, Department of International Health, Johns Hopkins Bloomberg School of Public \\ Health, 615 N. Wolfe Street, Room W2041, Baltimore, MD 21205 , USA: ${ }^{2} \mathrm{JiVitA}$ Maternal and Child Research \\ Project, Rangpur, Bangladesh
}

Submitted 12 January 2008: Accepted 5 February 2009: First published online 6 April 2009

\begin{abstract}
Objective: To assess the nutritional status and risk factors of undernutrition in post-menarcheal girls in rural northern Bangladesh.

Design: Cross-sectional data on anthropometric measurements, dietary intake, work activity, morbidity and socio-economic status were collected from 12- to 19year-old primigravidae ( $n$ 209) and never-pregnant adolescents ( $n$ 456) matched on age and time since menarche. Multiple regression analyses were conducted to determine predictors of stunting, thinness, upper-arm muscle (UAMZ) and fat area $Z$-scores (UAFZ) among the adolescent girls.

Results: A large proportion of adolescents (49\%) were stunted (height-for-age $Z$-score $<-2)$ and underweight ( $40 \%$; weight-for-age $Z$-score $<-2$ ), but not thin (BMI-for-age $<5$ th percentile; $\sim 10 \%$ ). The mean (sD) UAMZ and UAFZ of the adolescent girls was $-0.3(0.64)$ and $-0.9(0 \cdot 40)$, respectively. Lean mass increased whereas fat mass declined with age. Both stunting and thinness were positively associated with age and time since menarche $(P<0 \cdot 05)$. Young age (12-14 years) and literacy were protective against stunting among pregnant adolescents $(\mathrm{OR}=0 \cdot 29,95 \% \mathrm{CI} 0 \cdot 09,0 \cdot 88$ and $\mathrm{OR}=0 \cdot 50,95 \%$ CI $0 \cdot 26,0 \cdot 96$, respectively). Having symptoms of diarrhoea or dysentery (OR $=7 \cdot 40,95 \%$ CI $1.43,38 \cdot 29)$ predicted thinness and was associated with lower UAMZ and UAFZ among never-pregnant girls (both $P<0 \cdot 05$ ). Performing light-to-moderate activities was protective against thinness among never-pregnant girls (OR $=0 \cdot 43$, $95 \%$ CI $0 \cdot 22,0 \cdot 82$ ), whereas pregnant adolescents who performed high levels of strenuous activities had greater UAMZ $(P<0 \cdot 05)$.

Conclusion: Undernutrition was widespread among this post-menarcheal adolescent population. Younger and literate adolescents were less likely to be stunted, whereas thinness and body composition were associated with morbidity and work activity.
\end{abstract}

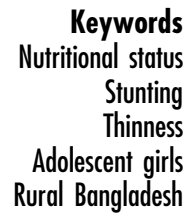

Adolescents comprise $20 \%$ of the world's population, of which more than $80 \%$ reside in developing countries ${ }^{(1)}$. Approximately $50 \%$ of adult body weight and $15 \%$ of final adult height is attained during adolescence ${ }^{(2)}$. Adolescence has been proposed to be the last window of opportunity to compensate for at least a portion of the growth deficits occurred in early childhood, although empirical evidence for this is weak ${ }^{(3-5)}$.

There is limited information available on the nutritional status of adolescents in developing countries. A crosssectional study of children aged 7-17 years from five countries in Africa and South Asia reported an overall prevalence of $51 \%$ for stunting and $48 \%$ for underweight, defined as height-for-age and weight-for-age $Z$-scores less than -2 , respectively, using the National Center for Health Statistics (NCHS) reference standards ${ }^{(6)}$. Reduced productivity, poor school performance and adverse reproductive outcomes are well-known consequences of malnutrition in this age group ${ }^{(6)}$. In Bangladesh, more than three-quarters of the 28 million adolescents live in rural areas, among which malnutrition has been shown to be pervasive, with $48 \%$ and $60 \%$ of adolescent girls being stunted and thin (BMI-for-age $<5$ th percentile using the NCHS reference), respectively ${ }^{(7)}$.

The nutritional status of adolescent girls is closely linked to the health and well-being of future generations. Premature childbearing resulting from marriage at an early age is common in underdeveloped countries. 
Menarche has been suggested to trigger parents to place their daughters on the marriage 'market' ${ }^{(8,9)}$. In rural Bangladesh, more than $60 \%$ of adolescents are married between the ages of 15 and 19 years, and pregnancy occurs on average 1.7 years after marriage ${ }^{(10,11)}$. Early pregnancy results in various adverse outcomes such as premature birth, low birth weight, and neonatal and maternal mortality, and undernutrition likely exacerbates these outcomes ${ }^{(11,12)}$.

We conducted a prospective cohort study of 12- to 19year-old girls in a rural area of Bangladesh in order to examine the consequences of pregnancy and lactation at an early age on the physical growth and body composition of young mothers. The analysis in the present paper uses data collected at baseline to examine the nutritional status of adolescent girls using measures of height, weight and body composition. Specifically, it explores demographic, socioeconomic, dietary, physical work activity and other factors associated with stunting, thinness and upper-arm muscle and fat area $Z$-scores in adolescent girls.

\section{Experimental methods}

\section{Study area and subjects}

Data were collected as part of a prospective cohort study on pregnancy and lactation and its influence on adolescent growth and nutritional status in the district of Gaibandha in rural north-west Bangladesh. The study was carried out as part of a randomized placebo-controlled trial assessing the impact of an antenatal weekly vitamin A or $\beta$-carotene supplement on maternal and infant mortality (called the JiVitA Project) started in August 2002. The JiVitA study area comprised 596 study-defined clusters called sectors (each sector was a small community of $\sim 200$ households), covering a total population of $\sim 580000$. In July 2004, ninety-six sectors were selected for conducting the prospective adolescent growth study. Every household in these sectors was visited to enumerate all married and unmarried female adolescents aged $<20$ years. Data on date of birth, month and year of menarche, marital status and pregnancy history were collected by interviewing the adolescent and her parents during the home visit. Home records of date of birth, if available, were used; in their absence, a selfreported year and month of birth after parental confirmation was used. Adolescents who had reached menarche were asked to recall the year and month of its occurrence; help of the mother or other female relatives living in the household was sought to aid recall. Those currently or previously pregnant, pre-menarcheal, or $<12$ years or $>19$ years of age were excluded. The resulting set of enumerated adolescents comprised 2605 married nulligravid ( $n$ 385) and unmarried ( $n$ 2220) adolescents, aged 12-19 years, who were post-menarcheal.

As part of the JiVitA trial that enrolled incident pregnancies through an active pregnancy surveillance, married adolescents were visited once every five weeks, asked if they had menstruated in the past $30 \mathrm{~d}$ and, if amenstrual, offered a urine pregnancy test based on determination of human chorionic gonadotrophin. Adolescents who tested positive were enrolled in the trial and began receiving their allocated weekly supplement. As part of the adolescent growth study, each time an adolescent was identified being pregnant, two never-pregnant adolescents were randomly selected matched on age and time since menarche. Consenting pregnant (also participants in the JiVitA trial) and never-pregnant adolescents were enrolled into the adolescent study and concurrently followed for a year to assess if pregnancy and lactation during adolescence altered the growth and nutritional status of young mothers. Interviews and anthropometric measurements were conducted at baseline and at the 12-month follow-up. The sample size for the study was 218 pregnant and 436 never-pregnant adolescents. A total of 229 pregnant and 456 neverpregnant adolescents were enrolled into the study between April and November 2005. The present analysis utilizes the baseline interview and anthropometric data on these adolescents.

\section{Baseline assessment and data collection}

Pregnant adolescents were visited in their home, within 1 (SD 1.5) weeks of pregnancy ascertainment, for conducting an interview and taking anthropometric measurements. Data on socio-economic status (SES), morbidity symptoms experienced in the previous month, a $7 \mathrm{~d}$ food frequency recall of thirty different selected food items, a $7 \mathrm{~d}$ physical work activity history, smoking and alcohol consumption, and personal hygiene were collected. Anthropometric assessments included weight, height, mid-upper arm circumference (MUAC), triceps (TSF) and subscapular (SSF) skinfold thicknesses. Baseline measurements in pregnant adolescents were done at a mean (sD) gestational age of $9 \cdot 7(2 \cdot 8)$ weeks. The early firsttrimester anthropometric measurements that were unlikely to undergo change were considered to be proxy for pre-pregnancy measurements. Never-pregnant girls were assessed within a week of the assessments done on their pregnant counterparts.

Anthropometric measurements were taken following standard procedures ${ }^{(13)}$. Height was recorded to the nearest $0 \cdot 1 \mathrm{~cm}$ using a Harpenden stadiometer (Shorr Productions, RI, USA) and weight was taken to the nearest $0 \cdot 1 \mathrm{~kg}$ using a digital scale (UNICEF scale S0141015; SECA Ltd, Birmingham, UK). Both TSF and SSF were measured to the nearest $0 \cdot 2 \mathrm{~mm}$ using Holtain callipers (Holtain Ltd, Dyfed, Wales) and MUAC to the nearest $0 \cdot 1 \mathrm{~cm}$ using a non-stretchable locally manufactured insertion tape based on the Ross non-elastic tape design (Ross Laboratories, Columbus, $\mathrm{OH}, \mathrm{USA})$. All measurements except weight were taken three times and the median value of each measurement was used. 
Eight female interviewers/anthropometrists who were trained and standardized at the start of the study conducted all interviews and measurements. The technical error of measurement (TEM) was estimated by asking each worker to measure a group of ten to fifteen women twice with an hour between measurements ${ }^{(14)}$. The mean intra- and inter-observer TEM of eight female interviewers at baseline was, respectively, 0.25 and $0.36 \mathrm{~cm}$ for height; 0.2 and $0.24 \mathrm{~cm}$ for MUAC; 0.66 and $0.84 \mathrm{~mm}$ for TSF; and 0.58 and $0.62 \mathrm{~mm}$ for SSF. These values are about half the cut-off of suggested acceptable TEM values ${ }^{(15)}$.

\section{Statistical analyses}

BMI was defined as weight divided by the square of height $\left(\mathrm{kg} / \mathrm{m}^{2}\right) . Z$-scores of height-for-age (HAZ), weightfor-age (WAZ) and BMI-for-age (BMIZ) were calculated using the Centers for Disease Control and Prevention (CDC, 2000) reference standards in EpiInfo 2005 software (CDC, Atlanta, GA, USA). Stunting and underweight were defined as HAZ and WAZ less than -2 , respectively, and thinness was defined as BMI-for-age $<5$ th percentile of the 2000 CDC reference. Upper-arm muscle (UAM) and fat areas (UAF) were computed using MUAC and TSF, as described by Frisancho, and corresponding $Z$-scores (UAMZ and UAFZ) were estimated using the age- and gender-specific means and standard deviations from the National Health and Nutrition Examination Surveys I and $\mathrm{II}^{(16)}$. Percentage body fat (\%BF) was derived from TSF and SSF as described by Slaughter $e t a l .{ }^{(17)}$ using the equation:

$\% \mathrm{BF}=1.33 \times(\mathrm{SSF}+\mathrm{TSF})-0.013 \times(\mathrm{SSF}+\mathrm{TSF})^{2}-2 \cdot 5$.

Categorical variables were created by applying appropriate cut-offs: $7 \mathrm{~d}$ food frequency data were used to classify into six food groups (meat \& eggs, fish, milk \& dairy, vegetable, fruits, beans) and to dichotomize each one into $\leq 3$ or $>3$ times per week; $7 \mathrm{~d}$ work activities were classified into strenuous (carrying heavy objects, working in the field, chopping firewood, sweeping, pounding grain, etc.) $v$. light-to-moderate (washing dishes, cooking, caring for animals, etc.) and dichotomized into $\leq 2$ or $>2$ activities per day; and morbidity variables were grouped and dichotomized into no morbidity $v$. any days of illness in the past $30 \mathrm{~d}$. Data on SES were grouped into five categories: dwelling characteristics, land ownership, productive assets, durable assets and human capital. A wealth index was developed based on these categories (S Gunnsteinsson, AB Labrique, KP West Jr, P Christian, S Mehra, AA Shamim, M Rashid, J Katz and R Klemm, unpublished results) using principal components analysis ${ }^{(18)}$.

Of the 229 pregnant and 456 never-pregnant adolescents who were enrolled into the study, pregnant girls ( $n$ 20) enrolled after 16 weeks of gestation were excluded because their baseline anthropometric measurements were less likely to be proxy for pre-pregnancy measurements. Basic characteristics were compared between pregnant and never-pregnant adolescents using $t$ tests and $\chi^{2}$ tests. Scatter plots with lowess curves ${ }^{(19)}$ were used to examine the distributions of height and BMI by age and time since menarche. A non-parametric trend test was performed to examine the trends in HAZ and BMIZ and the prevalence of stunting and thinness by strata of age and time since menarche.

Analyses were performed separately for pregnant and never-pregnant adolescents because the two groups of adolescents were found to differ on a number of characteristics in the exploratory data analysis. To identify factors associated with stunting and thinness, bivariate analyses were performed for all the various risk factors using a $\chi^{2}$ test. Risk factors included SES, dietary intake, morbidity and physical work activity. Factors that were significantly associated with stunting or thinness in the bivariate analyses $(P<0 \cdot 05)$ were included in the multiple logistic regression models in addition to age and time since menarche. Separate logistic regression models were constructed for stunting and thinness. Similarly, factors associated with UAMZ and UAFZ in the bivariate analyses using $t$ tests $(P<0.05)$ were included in the multiple linear regression models with either UAMZ or UAFZ as the dependent variable. All analyses were performed using the STATA statistical software package version $8 \cdot 0$ (Stata Corp., College Station, TX, USA).

The study was approved by the Bangladesh Medical Research Council, Dhaka, Bangladesh and the Committee on Human Research at the Bloomberg School of Public Health, Johns Hopkins University, Baltimore, MD, USA.

\section{Results}

The mean (SD) age and age at menarche of the adolescents in the analysis ( $n$ 665) was $16 \cdot 3(1 \cdot 6)$ years and $12 \cdot 7$ $(1 \cdot 2)$ years, respectively. Pregnant and never-pregnant girls differed on a number of characteristics (Table 1). All pregnant adolescents (100\%) and only $16 \%$ of neverpregnant adolescents were married at the time of interview. More pregnant girls than never-pregnant girls reported symptoms of urinary tract infection (painful urination or lower abdominal pain; $52 \%$ v. $32 \%$, $P<0.001)$ and anaemia $(50 \% v .21 \%, P<0.001)$ in the previous month (Table 1). Strenuous work activities were rarely performed, with a higher proportion of pregnant than never-pregnant girls reporting chopping firewood $(12 \% v .7 \%, P<0.05)$ in the past week. Approximately half of the never-pregnant adolescents were enrolled in school at the time of interview, whereas none of the pregnant girls were attending school $(P<0 \cdot 05)$. Neverpregnant adolescents belonged to families with higher SES compared with pregnant adolescents $(P<0 \cdot 05)$.

The mean (SD) height, weight and BMI of the adolescent girls was $149 \cdot 4(5 \cdot 2) \mathrm{cm}, 42 \cdot 7(5 \cdot 4) \mathrm{kg}$ and $19 \cdot 1$ $(2 \cdot 0) \mathrm{kg} / \mathrm{m}^{2}$, respectively, with no significant differences between pregnant and never-pregnant adolescents matched 
Table 1 Characteristics of pregnant adolescents assessed early in gestation* and never-pregnant adolescentst in rural Bangladesh

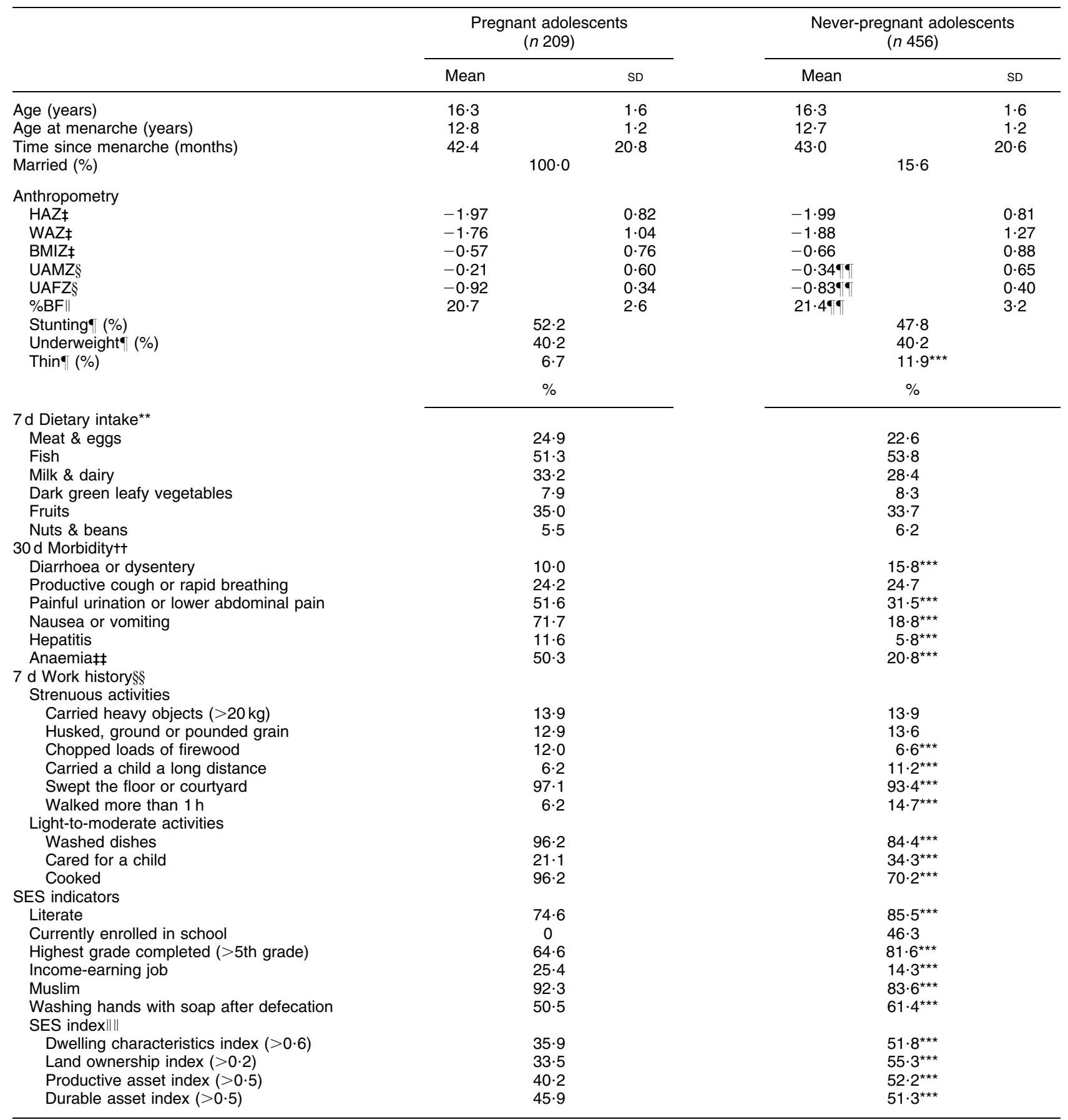

HAZ, height-for-age Z-score; WAZ, weight-for-age Z-score; BMIZ, BMI-for-age Z-score; UAMZ, upper-arm muscle area Z-score; UAFM, upper-arm fat area $Z$-score; \%BF, percentage body fat; SES, socio-economic status.

${ }^{*}$ Mean (SD) gestational age at measurement was $9 \cdot 7(2 \cdot 8)$ weeks.

tMissing values existed for weight $(n 1)$, $\operatorname{BMI}(n 1), \operatorname{UAMZ}(n 1), \operatorname{UAFZ}(n 1), \% \mathrm{BF}(n 3)$; meat \& eggs $(n 12)$, fish ( $n 33)$, milk \& dairy $(n 9)$, vegetables $(n 7)$, fruits ( $n 58)$; diarrhoea \& dysentery $(n 9)$, painful urination ( $n 28)$, productive cough ( $n 26)$, nausea \& vomiting $(n 30)$, symptoms of hepatitis $(n 16)$, anaemia $(n 8)$; carried heavy objects $(n 1)$, swept floor $(n 2)$.

¥HAZ, WAZ and BMIZ were calculated using the 2000 Centers for Disease Control and Prevention (CDC) reference.

$\S U A M Z$ and UAFZ were calculated using age- and gender-specific means and standard deviations from National Health and Nutrition Examination Surveys I and II ${ }^{(16)}$. $\| \% \mathrm{BF}=1.33 \times(\mathrm{SSF}+\mathrm{TSF})-0.013 \times(\mathrm{SSF}+\mathrm{TSF})^{2}-2 \cdot 5$, as described by Slaughter et al. ${ }^{(17)}$.

- Stunting and underweight were defined as HAZ and WAZ less than -2 , respectively. Thinness was defined as BMI-for-age $<5$ th percentile of the $2000 \mathrm{CDC}$ reference. ${ }^{* *}$ Percentage of adolescents who consumed each food group more than three times in the past $7 \mathrm{~d}$.

t+Percentage of adolescents who had each morbidity symptom at least once in the past $30 \mathrm{~d}$.

\#Percentage of adolescents who had at least three clinical symptoms of anaemia in the past $30 \mathrm{~d}$.

$\S \S$ Percentage of adolescents performing each work activity at least once in the past $7 \mathrm{~d}$.

\|\| Higher index score indicates higher SES.

- TMean value was significantly different from that of pregnant adolescents $(t$ test): $P<0.05$.

${ }_{* \star *}$ Percentage was significantly different from that of pregnant adolescents $\left(\chi^{2}\right.$ test): $P<0.05$. 

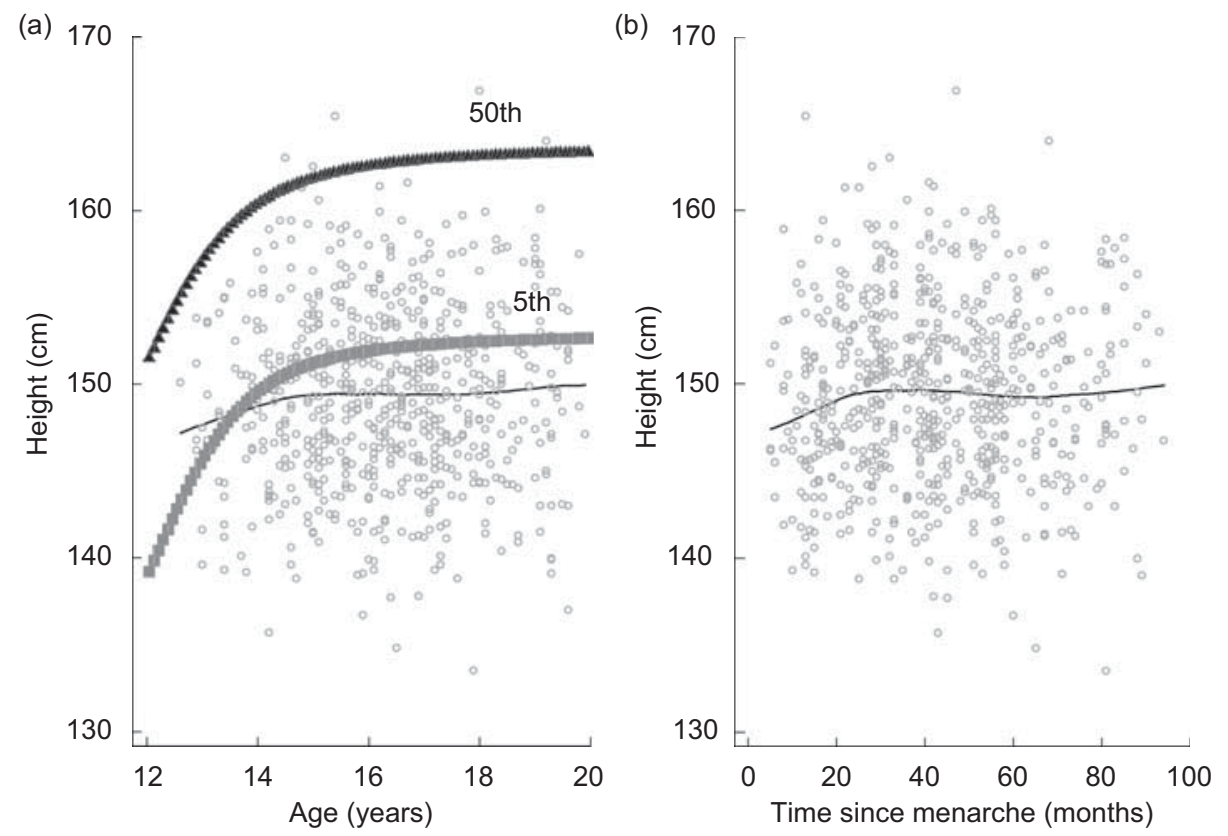

Fig. 1 Lowess curves and scatter plots of: (a) height by age, compared with the median and 5th percentile of the 2000 Centers for Disease Control and Prevention reference, and (b) height by time since menarche, among post-menarcheal adolescent girls in rural Bangladesh

on age and time since menarche. Undernutrition was widespread, with $\sim 50 \%$ being stunted and $\sim 40 \%$ being underweight (Table 1). Thinness was less common, but the prevalence among never-pregnant girls was higher than that in pregnant ones $(12 \% v .7 \%, P=0 \cdot 04)$. Mean (SD) UAM and UAMZ was $31 \cdot 3(4 \cdot 5) \mathrm{cm}^{2}$ and $-0 \cdot 3(0 \cdot 64)$, being higher among pregnant $v$. never-pregnant girls $\left(31 \cdot 9(4 \cdot 1) v .31 \cdot 0(4 \cdot 0) \mathrm{cm}^{2} ;-0 \cdot 21(0 \cdot 60) v .-0 \cdot 34(0 \cdot 65)\right.$, both $P=0 \cdot 01)$. On the other hand, mean (SD) UAFZ $(-0.83(0.40) v .-0.92(0.34), P<0.01)$ and \%BF $(21.4$ (SD 3.2) v. $20 \cdot 7$ (SD $2 \cdot 6$ ), $P<0 \cdot 01$ ) were higher among never-pregnant than pregnant girls (Table 1 ).

Height remained relatively constant across the ranges of age and time since menarche, although the difference with the median of the CDC reference (CDC, 2000) tended to increase with age (Fig. 1). Overall, BMI increased with age and time since menarche with the difference with the median of the CDC reference increasing gradually after about 14 years of age (Fig. 2). Thus both HAZ and BMIZ declined with age and time since menarche, causing the prevalence of stunting and thinness to increase with age (both $P$ for trend $<0 \cdot 05$; data not shown).

Few variables appeared to predict the risk of stunting in adolescents (Table 2). In the multivariate analysis, among pregnant adolescents, young age (12-14 years $v$. $>14$ years) and literacy were associated with a $71 \%(95 \%$ CI $12,91 \%)$ and a $50 \%$ (95\% CI 4, 74\%) lower odds of stunting. On the other hand, a shorter duration from menarche to first pregnancy ( $<24$ months $v$. $>24$ months) was associated with an increased odds of stunting $(\mathrm{OR}=3 \cdot 21,95 \%$ CI $1 \cdot 07-9 \cdot 65$; Table 2$)$. Neither morbidity nor food intake was associated with stunting (data not shown). None of these variables including age and time since menarche predicted the risk of stunting in the never-pregnant adolescents.

Thinness appeared to be associated with several factors (Table 3). Among pregnant adolescents, having diarrhoea or dysentery in the previous month was strongly associated with thinness (OR $=7 \cdot 40,95 \%$ CI $1 \cdot 43,38 \cdot 29)$. Among never-pregnant adolescents, performing more than two light-to-moderate activities per day $(\mathrm{OR}=0 \cdot 43$, $95 \%$ CI $0 \cdot 22,0 \cdot 82)$ and a history of symptoms of anaemia in the preceding month $(\mathrm{OR}=2 \cdot 72,95 \% \mathrm{CI} 1 \cdot 38,5 \cdot 37)$ predicted thinness.

There was a positive linear association between age and UAMZ among both pregnant and never-pregnant girls $(P<0.05$; Table 4). Performing more than two strenuous work activities per day was associated with greater UAMZ among pregnant girls, whereas symptoms of diarrhoea or dysentery in the previous month were associated with a lower UAMZ among never-pregnant girls (both $P<0 \cdot 05)$. Age was negatively associated with UAFZ $(P<0 \cdot 001)$ and symptoms of diarrhoea or dysentery in the past month was associated with lower UAFZ among never-pregnant adolescents $(P<0 \cdot 05$; Table 4$)$.

\section{Discussion}

We assessed the nutritional status of 12- to 19-year-old post-menarcheal adolescent girls in a rural area of Bangladesh and found undernutrition to be widespread in 

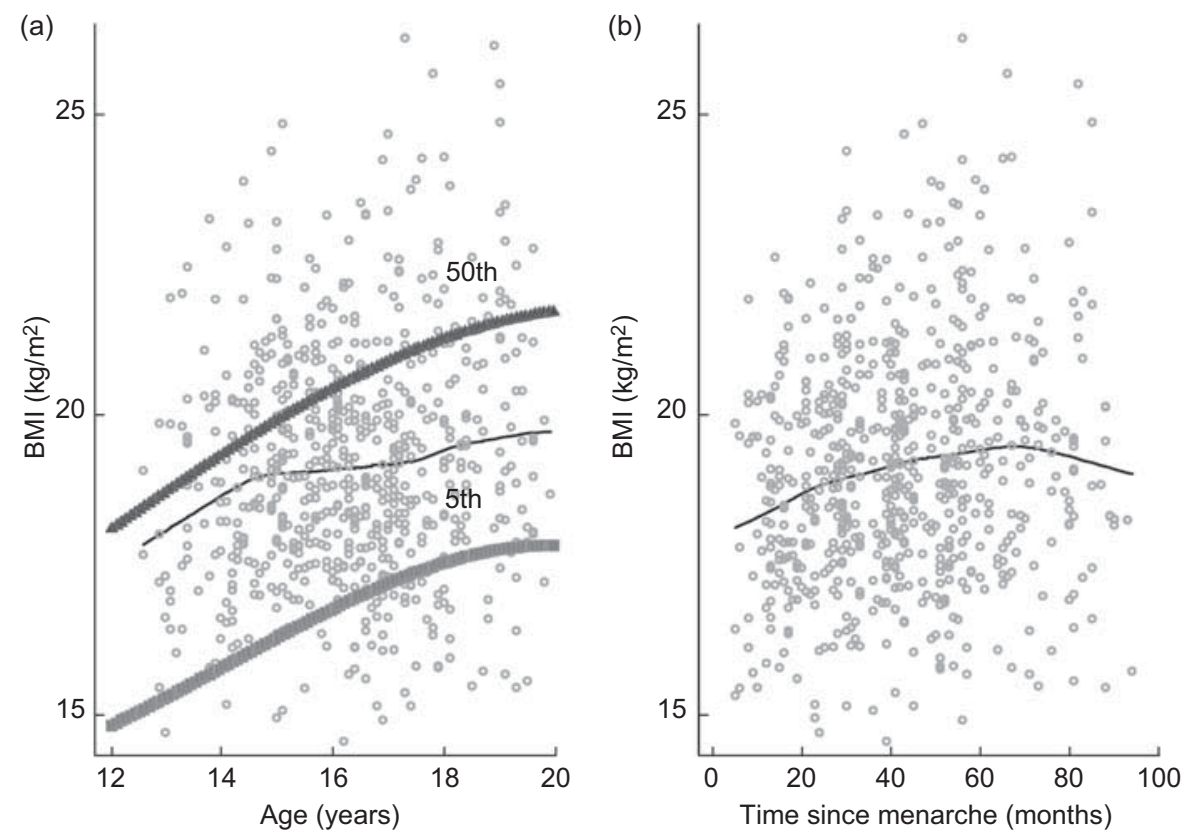

Fig. 2 Lowess curves and scatter plots of: (a) BMI by age, compared with the median and 5th percentile of the 2000 Centers for Disease Control and Prevention reference, and (b) BMI by time since menarche, among post-menarcheal adolescent girls in rural Bangladesh

Table 2 Risk factors of stunting for pregnant and never-pregnant adolescents in rural Bangladesh

\begin{tabular}{|c|c|c|c|c|c|c|c|c|c|c|c|c|}
\hline & \multicolumn{6}{|c|}{ Pregnant adolescents ( $n$ 209) } & \multicolumn{6}{|c|}{ Never-pregnant adolescents ( $n$ 456) } \\
\hline & \multirow[b]{2}{*}{$n$} & \multirow{2}{*}{$\begin{array}{l}\text { Stunting } \\
(\%)\end{array}$} & \multicolumn{2}{|r|}{ Crude } & \multicolumn{2}{|c|}{ Adjusted* } & \multirow[b]{2}{*}{$n$} & \multirow{2}{*}{$\begin{array}{c}\text { Stunting } \\
(\%)\end{array}$} & \multicolumn{2}{|r|}{ Crude } & \multicolumn{2}{|c|}{ Adjusted } \\
\hline & & & OR & $95 \% \mathrm{Cl}$ & OR & $95 \% \mathrm{Cl}$ & & & OR & $95 \% \mathrm{Cl}$ & OR & $95 \% \mathrm{Cl}$ \\
\hline \multicolumn{13}{|l|}{ Chronological age } \\
\hline $18-19$ years & 43 & $57 \cdot 5$ & $1 \cdot 00$ & Reference & $1 \cdot 00$ & Reference & 76 & $51 \cdot 3$ & $1 \cdot 00$ & Reference & $1 \cdot 00$ & Reference \\
\hline $15-17$ years & 126 & $52 \cdot 3$ & $0 \cdot 81$ & $0.27,1.53$ & 0.55 & $0 \cdot 24,1 \cdot 25$ & 282 & $52 \cdot 1$ & 1.09 & $0.92,1 \cdot 27$ & $1 \cdot 10$ & $0.61,1.99$ \\
\hline $12-14$ years & 40 & $46 \cdot 5$ & $0 \cdot 64$ & $0.27,1.53$ & 0.29 & $0.09,0.88$ & 98 & $32 \cdot 7$ & 0.56 & $0.29,1.08$ & 0.50 & $0.23,1.07$ \\
\hline \multicolumn{13}{|c|}{ Time since menarche } \\
\hline$\geq 60$ months & 41 & $59 \cdot 5$ & $1 \cdot 00$ & Reference & $1 \cdot 00$ & Reference & 95 & $53 \cdot 7$ & $1 \cdot 00$ & Reference & $1 \cdot 00$ & Reference \\
\hline 24-59 months & 126 & $51 \cdot 6$ & $1 \cdot 23$ & $0 \cdot 61,2 \cdot 50$ & $1 \cdot 70$ & $0 \cdot 75,3 \cdot 84$ & 273 & $48 \cdot 4$ & $0 \cdot 81$ & $0.51,1.29$ & 0.85 & $0.49,1 \cdot 47$ \\
\hline$<24$ months & 42 & $46 \cdot 3$ & $1 \cdot 70$ & $0 \cdot 71,4 \cdot 06$ & $3 \cdot 21$ & $1 \cdot 07,9 \cdot 65$ & 88 & $39 \cdot 8$ & 0.57 & $0 \cdot 32,1 \cdot 02$ & 0.94 & $0.45,1.98$ \\
\hline \multicolumn{13}{|c|}{ Light-to-moderate activity } \\
\hline$\leq 2$ activities/d & 84 & $51 \cdot 2$ & $1 \cdot 00$ & Reference & $1 \cdot 00$ & Reference & 248 & $43 \cdot 6$ & $1 \cdot 00$ & Reference & $1 \cdot 00$ & Reference \\
\hline$>2$ activities/d & 123 & $52 \cdot 9$ & 1.07 & $0 \cdot 61,1 \cdot 86$ & $1 \cdot 19$ & $0 \cdot 66,2 \cdot 13$ & 203 & $52 \cdot 7$ & $1 \cdot 44$ & $1 \cdot 00,2 \cdot 10$ & $1 \cdot 21$ & $0 \cdot 81,1 \cdot 81$ \\
\hline \multicolumn{13}{|l|}{ Literacy } \\
\hline Illiterate & 53 & $64 \cdot 2$ & $1 \cdot 00$ & Reference & $1 \cdot 00$ & Reference & 66 & $57 \cdot 6$ & $1 \cdot 00$ & Reference & $1 \cdot 00$ & Reference \\
\hline Literate & 156 & $48 \cdot 1$ & 0.52 & $0.27,0.98$ & 0.50 & $0.26,0.96$ & 390 & $46 \cdot 2$ & 0.63 & $0.37,1 \cdot 07$ & 0.78 & $0 \cdot 44,1 \cdot 41$ \\
\hline \multicolumn{13}{|c|}{ Current school enrolment } \\
\hline No & 209 & - & - & & - & & 53 & $64 \cdot 2$ & $1 \cdot 00$ & Reference & $1 \cdot 00$ & Reference \\
\hline Yes & 0 & - & - & & - & & 156 & $48 \cdot 1$ & 0.57 & $0.39,0.82$ & $0 \cdot 70$ & $0.45,1.08$ \\
\hline \multicolumn{13}{|c|}{ Employed for income-earning job } \\
\hline No & 156 & $51 \cdot 3$ & $1 \cdot 00$ & Reference & 1.00 & Reference & 391 & $45 \cdot 5$ & $1 \cdot 00$ & Reference & $1 \cdot 00$ & Reference \\
\hline Yes & 53 & $54 \cdot 7$ & $1 \cdot 15$ & $0 \cdot 61,2 \cdot 15$ & $1 \cdot 01$ & $0.51,1.97$ & 65 & $61 \cdot 5$ & 1.91 & $1 \cdot 12,3 \cdot 28$ & $1 \cdot 69$ & $0.97,2.97$ \\
\hline
\end{tabular}

*Using multiple logistic regression analysis.

this population, with nearly half of the adolescents being stunted and more than $40 \%$ underweight. Thinness, using low BMI $(<5$ th percentile of the reference standard) as an index, was found to be less common, and affected $\sim 10 \%$ of the girls. These girls also had low upper-arm muscle and fat mass area as reflected by mean (SD) UAMZ and UAFZ of $-0.3(0.64)$ and $-0.9(0.38)$, respectively.
By design, the study sample comprised post-menarcheal adolescents selected to be pregnant and never-pregnant matched on age and time since menarche in order to assess the impact of adolescent pregnancy on growth. Thus, our findings may not be generalizable to or comparable with other randomly sampled populations of adolescents in the same age range that include pre-menarcheal 
Table 3 Risk factors of thinness for pregnant and never-pregnant adolescents in rural Bangladesh

\begin{tabular}{|c|c|c|c|c|c|c|c|c|c|c|c|c|}
\hline & \multicolumn{6}{|c|}{ Pregnant adolescents ( $n$ 209) } & \multicolumn{6}{|c|}{ Never-pregnant adolescents ( $n$ 456) } \\
\hline & \multirow[b]{2}{*}{$n$} & \multirow{2}{*}{$\begin{array}{c}\text { Thinness } \\
(\%)\end{array}$} & \multicolumn{2}{|c|}{ Crude } & \multicolumn{2}{|c|}{ Adjusted* } & \multirow[b]{2}{*}{$n$} & \multirow{2}{*}{$\begin{array}{c}\text { Thinness } \\
(\%)\end{array}$} & \multicolumn{2}{|c|}{ Crude } & \multicolumn{2}{|c|}{ Adjusted } \\
\hline & & & OR & $95 \% \mathrm{Cl}$ & OR & $95 \% \mathrm{Cl}$ & & & OR & $95 \% \mathrm{Cl}$ & OR & $95 \% \mathrm{Cl}$ \\
\hline \multicolumn{13}{|l|}{ Chronological age } \\
\hline $18-19$ years & 40 & $12 \cdot 5$ & $1 \cdot 00$ & Reference & 1.00 & Reference & 76 & $17 \cdot 3$ & $1 \cdot 00$ & Reference & $1 \cdot 00$ & Reference \\
\hline $15-17$ years & 126 & $7 \cdot 1$ & $0.54 t$ & $0 \cdot 17,1 \cdot 71$ & $1 \cdot 75$ & $0 \cdot 35,8 \cdot 83$ & 282 & $13 \cdot 5$ & $0 \cdot 74$ & $0.37,1.48$ & $0 \cdot 80$ & $0.34,1.91$ \\
\hline $12-14$ years & 43 & 0 & - & & - & & 98 & $3 \cdot 1$ & $0 \cdot 15$ & $0.04,0.55$ & $0 \cdot 13$ & $0.03,0.60$ \\
\hline \multicolumn{13}{|c|}{ Time since menarche } \\
\hline$\geq 60$ months & 41 & $17 \cdot 1$ & 1.00 & Reference & 1.00 & Reference & 95 & $13 \cdot 8$ & $1 \cdot 00$ & Reference & $1 \cdot 00$ & Reference \\
\hline 24-59 months & 126 & $4 \cdot 8$ & 0.24 & $0 \cdot 08,0 \cdot 77$ & 0.22 & $0.05,0.92$ & 273 & $12 \cdot 1$ & $0 \cdot 86$ & $0 \cdot 43,1 \cdot 71$ & $1 \cdot 27$ & $0.54,2.95$ \\
\hline$<24$ months & 42 & $2 \cdot 4$ & $0 \cdot 12$ & $0.01,1.01$ & 0.28 & $0.03,3.06$ & 88 & $9 \cdot 1$ & 0.62 & $0.25,1.58$ & $1 \cdot 80$ & $0.56,5.79$ \\
\hline \multicolumn{13}{|c|}{ Light-to-moderate activity } \\
\hline$\leq 2$ activities/d & 84 & $6 \cdot 0$ & 1.00 & Reference & 1.00 & Reference & 248 & $15 \cdot 0$ & $1 \cdot 00$ & Reference & 1.00 & Reference \\
\hline$>2$ activities/d & 123 & $8 \cdot 3$ & 1.25 & $0 \cdot 40,3 \cdot 86$ & 1.01 & $0.26,3.95$ & 203 & $8 \cdot 4$ & 0.52 & $0.28,0.95$ & 0.43 & $0.22,0.82$ \\
\hline \multicolumn{13}{|c|}{ Diarrhoea or dysentery } \\
\hline No & 181 & $5 \cdot 5$ & 1.00 & Reference & 1.00 & Reference & 71 & $10 \cdot 4$ & $1 \cdot 00$ & Reference & 1.00 & Reference \\
\hline Yes & 20 & $20 \cdot 0$ & $4 \cdot 28$ & $1 \cdot 20,15 \cdot 19$ & $7 \cdot 40$ & $1 \cdot 43,38 \cdot 29$ & 383 & $19 \cdot 7$ & $2 \cdot 11$ & $1 \cdot 08,4 \cdot 12$ & $1 \cdot 58$ & $0.75,3 \cdot 31$ \\
\hline \multicolumn{13}{|c|}{ Painful urination or lower abdominal pain } \\
\hline No & 93 & $5 \cdot 4$ & 1.00 & Reference & 1.00 & Reference & 304 & $9 \cdot 2$ & $1 \cdot 00$ & Reference & 1.00 & Reference \\
\hline Yes & 99 & $7 \cdot 1$ & $1 \cdot 34$ & $0 \cdot 41,4 \cdot 38$ & 0.88 & $0 \cdot 24,3 \cdot 29$ & 140 & $17 \cdot 1$ & $2 \cdot 04$ & $1 \cdot 13,3 \cdot 67$ & 1.51 & $0 \cdot 79,2 \cdot 86$ \\
\hline \multicolumn{13}{|c|}{ Symptoms of anaemia } \\
\hline No & 100 & $6 \cdot 0$ & $1 \cdot 00$ & Reference & 1.00 & Reference & 360 & $8 \cdot 9$ & 1.00 & Reference & $1 \cdot 00$ & Reference \\
\hline Yes & 101 & $7 \cdot 9$ & $1 \cdot 35$ & $0.45,4.03$ & 0.83 & $0 \cdot 20,3 \cdot 49$ & 95 & $23 \cdot 2$ & 3.09 & $1 \cdot 70,5 \cdot 63$ & $2 \cdot 72$ & $1 \cdot 38,5 \cdot 37$ \\
\hline
\end{tabular}

*Using multiple logistic regression analysis.

tAge groups 12-14 and 15-17 years combined, as there were no pregnant adolescents (12-14 years) classified as thin 
Table 4 Factors associated with upper-arm muscle and fat area Z-scores (UAMZ and UMFZ, respectively) among pregnant and neverpregnant adolescents in rural Bangladesh

\begin{tabular}{|c|c|c|c|c|c|c|}
\hline & \multicolumn{3}{|c|}{ Pregnant adolescents $(n$ 209) } & \multicolumn{3}{|c|}{ Never-pregnant adolescents ( $n$ 456) } \\
\hline & \multicolumn{2}{|c|}{ Adjusted* $^{*}$} & \multirow[b]{2}{*}{$P$ value } & \multicolumn{2}{|c|}{ Adjusted } & \multirow[b]{2}{*}{$P$ value } \\
\hline & $\beta$ coefficient & SE & & $\beta$ coefficient & SE & \\
\hline \multicolumn{7}{|l|}{ UAMZ } \\
\hline Chronological age (years) & 0.09 & $0 \cdot 04$ & $<0.05$ & 0.07 & 0.03 & $<0.05$ \\
\hline Time since menarche (months) & 0.001 & 0.003 & $0 \cdot 82$ & 0.01 & 0.002 & $<0.01$ \\
\hline Diarrhoea or dysenteryt & -0.05 & $0 \cdot 14$ & $0 \cdot 74$ & $-0 \cdot 19$ & 0.09 & $<0.05$ \\
\hline Nausea or vomitingt & $-0 \cdot 10$ & 0.09 & $0 \cdot 30$ & $-0 \cdot 14$ & 0.08 & 0.07 \\
\hline Strenuous work activity $\ddagger$ & $0 \cdot 19$ & 0.09 & $<0.05$ & 0.05 & 0.06 & 0.44 \\
\hline Wealth index§ & -0.005 & 0.04 & 0.91 & 0.02 & 0.03 & 0.48 \\
\hline \multicolumn{7}{|l|}{ UMFZ } \\
\hline Chronological age (years) & -0.02 & 0.02 & $0 \cdot 28$ & -0.07 & 0.02 & $<0.001$ \\
\hline Time since menarche (months) & -0.002 & 0.002 & 0.21 & 0.004 & 0.001 & $<0.01$ \\
\hline Fish consumption $\|$ & -0.08 & 0.05 & $0 \cdot 10$ & 0.07 & 0.04 & 0.08 \\
\hline Diarrhoea or dysentery $\dagger$ & 0.001 & 0.08 & 0.99 & $-0 \cdot 11$ & 0.05 & $<0.05$ \\
\hline Nausea or vomitingt & 0.09 & 0.05 & 0.09 & -0.06 & 0.05 & $0 \cdot 26$ \\
\hline Anaemia & -0.04 & 0.05 & $0 \cdot 47$ & -0.07 & 0.05 & $0 \cdot 12$ \\
\hline Wealth index§ & 0.02 & 0.02 & 0.46 & 0.03 & 0.02 & 0.16 \\
\hline
\end{tabular}

*Using multiple linear regression analysis.

tHaving either morbidity symptom at least once in the past $30 \mathrm{~d}$.

¥Performing more than two strenuous work activities per day.

$\S$ Higher index score indicates higher socio-economic status.

$\|$ Consuming fish more than three times in the past $7 \mathrm{~d}$.

- Having at least three clinical symptoms of anaemia in the past $30 \mathrm{~d}$.

girls and/or exclude pregnant adolescents. We did, however, stratify our results by pregnant and neverpregnant adolescents. And yet, the high prevalence of undernutrition in this population is comparable to previously reported rates of stunting (30-65\%) and underweight $(25-55 \%)$ in other developing countries ${ }^{(7,20)}$. In general, post-menarcheal girls tend to be taller and heavier than pre-menarcheal girls of the same age ${ }^{(21)}$. Thus, although unassessed, it is likely that the prevalence of undernutrition in our population may be even higher among adolescents of a similar age range but who have not yet attained menarche.

Unlike our study, Chowdhury et al. found that nearly $60 \%$ of rural Bangladeshi unmarried girls aged 10-17 years were thin (BMI-for-age $<5$ th percentile using the NCHS reference $)^{(22)}$. The difference may be explained by the large proportion (67\%) of pre-menarcheal and, therefore, younger adolescents included in their study compared with the present study, in which all adolescents were post-menarcheal. BMI increases throughout adolescence even after the onset of menarche, and postmenarcheal adolescents tend to have higher BMI than pre-menarcheal girls of the same age ${ }^{(22)}$.

In the present study, although data are cross-sectional, there was an apparent increase in the prevalence of stunting and thinness from 12 to 17 years of age. Age was positively associated with UAMZ but negatively associated with UAFZ, indicating perhaps a progressive catchup growth in lean body mass with a relative decrease in fat mass as the adolescents became older. Previous studies of adolescent girls in Africa have found a progressive decline in the prevalence of stunting after 12 years of age, reflecting perhaps late pubertal catch-up in linear growth $^{(23-25)}$. This may indicate that the nutritional status of rural Bangladeshi adolescent girls deteriorates progressively with age and that the late pubertal catch-up growth observed among African adolescent girls may not be taking place in the present post-menarcheal population. It is likely that younger adolescents who have attained menarche are early maturers who are better nourished than pre-menarcheal girls of the same age. The prevalence of undernutrition is therefore likely to be higher among the girls who are older when they reach menarche.

The differences between pregnant and never-pregnant girls are worth mentioning. All pregnant girls in our study were married at the time of interview, while less than a quarter of never-pregnant girls were married. While teenage births outside marriage have been increasing in developed countries, the large majority of adolescent childbearing occurs within marriage in underdeveloped countries, as pregnancy outside marriage is still considered inappropriate from cultural, social and religious perspectives ${ }^{(26)}$. In rural areas of the developing world, pregnancy tends to occur shortly after marriage among adolescent girls due to the low contraceptive use that may be explained by 'lack of knowledge, lack of personal autonomy, limited financial resources, and pressure to demonstrate fertility soon after marriage ${ }^{,(27)}$. Neverpregnant girls in our study came from families with higher SES and were more likely to be literate, have completed primary education and be enrolled in school at the time of interview than pregnant adolescents. Evidence from around the world suggests that female education delays 
age at first marriage and pregnancy by improving selfesteem and income-earning opportunities of teenage girls $^{(27)}$. More pregnant girls than never-pregnant girls were performing physical work activities such as chopping firewood, sweeping, washing dishes and cooking. In rural Bangladesh, adolescent girls tend to become responsible for most of the household chores once they are married ${ }^{(28)}$. This may, in part, explain the higher lean body mass but lower fat mass and \%BF among pregnant than never-pregnant girls in our study. A higher proportion of pregnant adolescents reported having symptoms of urinary tract infection, hepatitis and anaemia compared with never-pregnant ones, because these conditions are likely to be affected by pregnancy.

The present study examined potential risk factors of stunting and thinness among pregnant and never-pregnant adolescent girls in rural Bangladesh. Stunting is more likely to be affected by early childhood growth and longterm lifestyle factors, but we were able to explore only the cross-sectional predictors of stunting that were measured concurrently. As a result, few variables explained the variability in the risk of stunting in this population. It is accepted that stunting occurs primarily during early childhood and that adolescence is a period of no additional growth faltering, although catch-up growth may occur to compensate for earlier growth deficits ${ }^{(29)}$. In a longitudinal study of rural Senegalese adolescents, preschool height, age and gender accounted for nearly $60 \%$ of the variance in adolescent height ${ }^{(25)}$, implying that adolescent height is largely determined by early childhood and the pre-pubertal growth experience. In the present study, aside from young age, literacy reduced the risk of stunting, reflecting an inverse association between perhaps SES and stunting among adolescents, as shown in previous cross-sectional and longitudinal studies ${ }^{(25,30)}$.

In contrast, more variables appeared to be associated with thinness, which is more likely to reflect the current nutritional status of adolescent girls. We hypothesized that high activity burden would increase the risk of undernutrition. However, we found that performing at least two activities of light-to-moderate intensity per day compared with fewer activities was protective for thinness at least among never-pregnant girls. This is similar to a rural Senegalese study in which adolescent girls with higher BMI and fat and lean body mass were more active, using accelerometer-assessed movement counts ${ }^{(31)}$. It is possible that better nourished girls are healthier and are more likely to perform physical work. On the other hand, in a longitudinal study of undernourished lactating Filipino women, the positive association between energy expenditure and weight was explained by a 'physical conditioning effect', such that high levels of physical activity resulted in a greater muscle mass in women ${ }^{(32)}$. In our study pregnant adolescents who performed high levels of strenuous work activities had a greater lean body mass.
The association between infections such as diarrhoea and undernutrition has been well documented in young children $^{(33)}$. A history of diarrhoea or dysentery in the previous month also increased the risk of thinness in the present study. Adolescents who reported having symptoms of anaemia in the past month were more likely to be thin than those who were non-anaemic. This corresponds with previous findings from Indonesia in which thinness was more prevalent among adolescents who had Fedeficiency anaemia ${ }^{(34)}$. It has been postulated that loss of appetite, one of the symptoms of anaemia, may be responsible for growth retardation among anaemic children $^{(35)}$.

We were limited by not having data on energy intake in better understanding the association between diet and undernutrition in adolescents. Also, in this setting information on the duration and intensity of physical activity was hard to collect. Finally, assessment of micronutrient deficiency was limited to the use of symptoms of anaemia, a crude measure of Fe deficiency, as we did not conduct $\mathrm{Hb}$ assessment. The sensitivity of anaemia-associated symptoms, such as severe headache, has been shown to be high $(\sim 80 \%)$, but the specificity is low $(\sim 30 \%)^{(36)}$. In addition, the positive predictive value of general symptoms of anaemia may be low as well.

In conclusion, stunting was highly prevalent among post-menarcheal pregnant and never-pregnant adolescent girls in rural Bangladesh. In this rural setting in Bangladesh, pregnant adolescents are more likely to be married, dropped out from school and from households with low SES, suggesting the need for continued efforts in delaying age of marriage and first pregnancy. The age trends in the prevalence of stunting and wasting malnutrition need to be confirmed with more research using random samples of adolescent girls in the South Asian context. Few concurrently measured variables such as diet, physical activity and morbidity predicted the risk of stunting, reflecting the notion that adolescent height is largely determined by early childhood and the pre-pubertal growth experience. Future studies with precise estimates of energy intake and expenditure and micronutrient status over an extended period of time preceding menarche are warranted to better understand nutritional status of adolescents in the developing world.

\section{Acknowledgements}

Sources of funding: The study was supported by the United States Agency for International Development, the Bill and Melinda Gates Foundation, and the Government of Bangladesh. Conflict of interest declaration: None declared. Authorship responsibilities: J.H.R. conducted the analysis, wrote the manuscript, designed the study and methodology, and was responsible for the management and implementation of the study. P.C. was involved 
in conceptualization of the study design and methodology, and contributed in the interpretation of the results and editing the manuscript. A.A.S., A.B.L. and M.R. helped direct and manage field implementation and were involved in study design and development of procedures. U.T.A. helped in the development of forms and procedures and study implementation.

\section{References}

1. UNICEF (2000) The State of the World's Children 2000. Geneva: UN.

2. Spear BA (2002) Adolescent growth and development. J Am Diet Assoc 102, Suppl., S23-S29.

3. Cameron N, Gordon-Larsen P \& Wrchota EM (1994) Longitudinal analysis of adolescent growth in height, fatness, and fat patterning in rural South African black children. Am J Phys Anthropol 93, 307-321.

4. Proos LA, Hofvander Y \& Tuvemo T (1991) Menarcheal age and growth pattern of Indian girls adopted in Sweden. II. Catch-up growth and final height. Indian J Pediatr $\mathbf{5 8}$, 105-114.

5. Steckel RH (1987) Growth depression and recovery: the remarkable case of American slaves. Ann Hum Biol 14, 111-132.

6. Partnership for Child Development (1998) The anthropometric status of schoolchildren in five countries in the Partnership for Child Development. Proc Nutr Soc 57, 149-158.

7. Shahabuddin AK, Talukder K, Talukder MK, Hassan M, Seal A, Rahman Q, Mannan A, Tomkins A \& Costello A (2000) Adolescent nutrition in a rural community in Bangladesh. Indian J Pediatr 67, 93-98.

8. Chowdhury AK (1983) Application of a marriage model in rural Bangladesh. J Biosoc Sci 15, 281-287.

9. Udry JR \& Cliquet RL (1982) A cross-cultural examination of the relationship between ages at menarche, marriage, and first birth. Demography 19, 53-63.

10. Alam N (2000) Teenage motherhood and infant mortality in Bangladesh: maternal age-dependent effect of parity one. J Biosoc Sci 32, 229-236.

11. Rahman S, Nessa F, Rahman S, Ali R \& Ali HA (1989) Reproductive health of adolescents in Bangladesh. Int J Gynecol Obstet 29, 329-335.

12. Stewart CP, Katz J, Khatry SK, LeClerq SC, Shrestha SR, West KP \& Christian P (2007) Preterm delivery but not intrauterine growth retardation is associated with young maternal age among primiparae in rural Nepal. Matern Child Nutr 3, 174-185.

13. Gibson RS (1990) Principles of Nutritional Assessment. New York: Oxford University Press.

14. Ulijaszek SJ \& Kerr DA (1999) Anthropometric measurement error and the assessment of nutritional status. $\mathrm{Br} \mathrm{J}$ Nutr 82, 165-177.

15. Shorr I (1986) How to Weigh and Measure Children. New York: UN Department of Technical Cooperation and Development and Statistical Office.

16. Frisancho AR (1990) Anthropometric Standards for the Assessment of Growth and Nutritional Status. Ann Arbor, MI: University of Michigan Press.

17. Slaughter MH, Lohman TG, Boileau RA, Horswill CA, Stillman RJ, Van Loan MD \& Bemben DA (1988) Skinfold equations for estimation of body fatness in children and youth. Hum Biol 60, 709-723.
18. Vyas S \& Kumaranayake L (2006) Constructing socioeconomic status indices: how to use principal components analysis. Health Policy Plan 21, 459-468.

19. Hastie TJ \& Tibshirani RJ (1990) Generalized Additive Models. New York: Chapman and Hall.

20. Kurz KM (1996) Adolescent nutritional status in developing countries. Proc Nutr Soc 55, 321-331.

21. Simondon KB, Simon I \& Simondon F (1997) Nutritional status and age at menarche of Senegalese adolescents. Ann Hum Biol 24, 521-532.

22. Chowdhury S, Shahabuddin AK, Seal AJ, Talukder KK, Hassan Q, Begum RA, Rahman Q, Tomkins A, Costello A \& Talukder MQ (2000) Nutritional status and age at menarche in a rural area of Bangladesh. Ann Hum Biol 27, 249-256.

23. Leenstra T, Petersen LT, Kariuki SK, Oloo AJ, Kager PA \& ter Kuile FO (2005) Prevalence and severity of malnutrition and age at menarche; cross-sectional studies in adolescent schoolgirls in western Kenya. Eur J Clin Nutr 59, 41-48.

24. Lwambo NJS, Brooker S, Size JE, Bundy DAP \& Guyatt H (2000) Age patterns in stunting and anemia in African schoolchildren: a cross-sectional study in Tanzania. Eur J Clin Nutr 54, 36-40.

25. Simondon KB, Simondon F, Simon I, Diallo A, Benefice E, Traissac P \& Maire B (1998) Preschool stunting, age at menarche and adolescent height: a longitudinal study in rural Senegal. Eur J Clin Nutr 52, 412-418.

26. Bongaarts J \& Cohen B (1998) Adolescent reproductive behavior in the developing world. Stud Fam Plann 29, 99-105.

27. Save the Children (2004) State of the World's Mother 2004: Children Having Children. Westport, CT: Save the Children.

28. Barkat A \& Majid M (2003) Adolescent Reproductive Health in Bangladesh: Status, Policies, Programs, and Issues. Washington, DC: Futures Group International POLICY Project.

29. Stoltzfus RJ (2001) Growth of school-age children. In Nutrition and Growth. Nestlé Nutrition Workshop Series: Pediatric Program vol. 47, pp. 257-280 [R Martorell and F Haschke, editors]. Vevey/Philadelphia, PA: Nestec Ltd/ Lippincott Williams \& Wilkins.

30. Linhares EDR, Round JM \& Jones DA (1986) Growth, bone maturation, and biochemical changes in Brazilian children from two different socioeconomic groups. Am J Clin Nutr 44, 552-558.

31. Benefice E, Garnier D \& Ndiaye AG (2001) Assessment of physical activity among rural Senegalese adolescent girls: influence of age, sexual maturation, and body composition. J Adolesc Health 28, 319-327.

32. Adair LS \& Popkin BM (1992) Prolonged lactation contributed to depletion of maternal energy reserves in Filipino women. J Nutr 122, 1643-1655.

33. Vella V, Tomkins A, Borghesi A, Milgliori GB, Adriko BC \& Crevatin E (1992) Determinants of child nutrition and mortality in north-west Uganda. Bull World Health Organ 70, 637-643.

34. Kurniawan YAI, Mulimatun S, Achadi EL \& Sastroamidjojo S (2006) Anemia and iron deficiency anemia among young adolescent girls from peri urban coastal area of Indonesia. Asia Pac J Clin Nutr 15, 350-356.

35. Chwang LC, Soemantri AG \& Pollitt E (1988) Iron supplementation and physical growth of rural Indonesian children. Am J Clin Nutr 47, 496-501.

36. Jackson RT (1992) Hemoglobin levels and anemia-associated symptoms in pregnant Liberian women. Nutrition $\mathbf{8}$, 430-433. 